\title{
Mid and Long Term Echocardiographic and Clinical Follow up of Treated Rheumatic Mitral Stenosis Patients
}

\author{
Lotfian Iman ${ }^{1}$, Shabestari Mahmoud ${ }^{1}$, Ebrahimi Mahmood ${ }^{1}$, Falsoleiman Homa ${ }^{1}$, Moohebati Mohsen ${ }^{1}$, Poorzand \\ Hoorak $^{1}$, Iravani Fateme ${ }^{1} \&$ Jalal Yazdi Majid ${ }^{1}$ \\ ${ }^{1}$ Department of cardiology, Faculty of Medicine, Mashhad University of medical Sciences, Mashhad, Iran \\ Correspondence: Jalal Yazdi Majid, Cardiologist, assistant professor, Department of cardiology, Faculty of \\ Medicine, Mashhad University of medical Sciences, Mashhad, Iran. E-mail: jalalyazdim@mums.ac.ir
}

Received: December 21, 2019

Accepted: January 22, 2020

Online Published: March 30, 2020

doi:10.5539/jmbr.v10n1p66

URL: https://doi.org/10.5539/jmbr.v10n1p66

\begin{abstract}
Introduction: Rheumatic mitral stenosis (MS) is a common valvopathy in developing countries that requires invasive or minimally invasive treatment. There is scarcity of data regarding the long term follow up of treated MS patients.

Aim: The aim of this study was to compare the long-term outcomes of biologic and mechanical prosthesis and percutaneous transvenous mitral commissurotomy (PTMC) in treated MS patients.

Materials and Methods: This historical cohort study was conducted on treated MS patients who underwent treatment in a tertiary hospital in Mashhad, Iran. Treated MS patients were identified and asked to refer to the center for follow up. Demographic characteristics and type of treatment intervention were obtained from patient records. The follow up assessment included history of PTMC, readmission and echocardiography to assess trans mitral gradient (MG), size and function of right ventricle (RV) and the presence and severity of other valvopathies. Results: A total of 135 patients $(21.5 \%$ males and $78.5 \%$ females) with the mean age of $43.68 \pm 11.17$ years old participated in the study. The most common intervention method was mechanical valve (61.5\%) followed by PTMC (24.4\%) and biologic valve (14.1\%). Median follow up duration was 4 years. Majority of subjects (52.6\%) remained asymptomatic and the functional class was reduced significantly compared to baseline. MG was significantly higher in PTMC and biological valve group compared to mechanical valve $\mathrm{p}<0.001)$. Mitral regurgitation (MR) was more prevalent in PTMC group $(\mathrm{p}<0.001)$ while abnormal RV size and function the least common in PTMC group ( $\mathrm{p}=0.014$ and $\mathrm{p}=0.002$ respectively).

Conclusions: All intervention groups resulted in improved functional class of MS patients but high prevalence of MR and lower prevalence of abnormal RV size and function were observed in PTMS group compared to surgical groups.
\end{abstract}

Keywords: Percutaneous Transvenous Mitral Commissurotomy, Biologic Mitral Valve Prosthesis, Mechanical Mitral Valve, Follow up, Mitral Stenosis, Mitral Valvuloplasty

\section{Introduction}

Mitral stenosis (MS) is among the most common valvular heart diseases in developing countries including Iran (Saxena, 2018; Wunderlich, Beigel, \& Siegel, 2013) affecting life expectancy and damaging the quality of life (Marzangi et al., 2018). The primary treatment for MS was partial commissurotomy (Selzer \& Cohn, 1972). Balloon valvuloplasty was introduced by Inoue in 1982 and is being used ever since (Watanabe, 2016). There is scarcity of literature regarding the long term follow up of MS balloon valvuloplasty and its comparison with mitral valve replacement. In a study, balloon valvuloplasty patients were surveyed for 13 years and the preintervention mitral valve area and echocardiographic score were reported to be the predictors of mitral valve restenosis (Fawzy, 2009). In another study 15 year follow up of MS patients undergoing surgical valve replacement revealed that the need for valve replacement was significantly lower in mechanical valves compared to biologic prostheses (Al Mosa, Omair, Arifi, \& Najm, 2016). In another study, mortality and morbidity due to repeated valvuloplasty and prosthesis replacement were significantly related to preintervention echocardiographic score (Fawzy et al., 2007). In another study echocardiography score above 8 in balloon valvuloplasty patients was associated with mitral insufficiency in follow up (Palacios, Sanchez, Harrell, Weyman, \& Block, 2002). The aim of this study was to assess the mid term and long term follow up of patients with mitral stenosis who underwent valvuloplasty. 


\section{Materials and Methods}

This historical cohort was performed on patients with the history of rheumatic MS who underwent mitral valvuloplasty in the Cardiology Department of the Imam Reza Hospital, Mashhad, Iran from March 2008 to March 2018. The demographic and baseline data prior to valvuloplasty and the type of valvuloplasty were extracted form patient records. Patients were then contacted by the researchers and were invited to the hospital to perform follow up assessment including physical examination and echocardiography. Patients with the history of endocarditis were excluded for the study. In the follow up assessment history of further hospitalization and the reason for hospitalization were also recorded. Other information included type and size of the prosthetic valve in cases of surgical valve replacement. A written informed consent was obtained from all patients who were willing to participate in the study.

The primary outcome measures included need for repeated valvuloplasty in each treatment group, while secondary outcome measures included number of further hospital admissions related to MS treatment, recurrence of mitral stenosis, status of other heart valves, left ventricular function and pulmonary artery pressure as well as the size and function of right ventricle. The results were then compared between treatment groups.

The study protocol was approved by the Ethical Committee of the Mashhad University of Medical Sciences (Reg. No. IR.MUMS.MEDICAL.REC.1397.270).

\subsection{Statistical Analysis}

Data was analyzed using the statistical package for social sciences (SPSS) software version 16 (IBM Inc., Chicago, Il, USA). The Kolmogorov-Smirnov test was used to assess the normality of continuous data. Normally distributed variables were presented using mean and standard deviation $(\mathrm{SD})$ while non-normally distributed variables were presented using median and interquartile range (IQR). Categorical variables were presented using frequency and percentage. In order to compare normally distributed continuous variables between intervention groups, the oneway analysis of variance (ANOVA) test was used while the Kruskal-Wallis test was used to compare non-normally distributed variables between intervention groups. The chi square or Fisher exact test was used to compare the distribution pattern of the categorical variables between groups.

\section{Results}

A total of 135 patients $(29,21.5 \%$ males and $106,78.5 \%$ females) agreed to participate in the study. The baseline characteristics of the study subjects are presented in Table 1 . The mean age of the subjects at time of treatment intervention was $43.68 \pm 11.17$ years old. Mitral valve replacement using biological and mechanical valves were identified in $19(14.1 \%)$ and $83(61.5 \%)$ of the subjects respectively, while percutaneous transvenous mitral commissurotomy (PTMC) was performed in $33(24.4 \%)$ of the subjects. The mean body mass index of the subjects was $27.82 \pm 5.53 \mathrm{~kg} / \mathrm{m}^{2}$. Comparison of baseline characteristics of the subjects between intervention groups is presented in Table 1. There was a significant difference in the frequency of smoking $(\mathrm{p}<0.001)$, cardiac rhythm $(p=0.027)$ and the extent of mitral regurgitation $(p<0.001)$ between intervention groups at baseline (Table 1$)$. The mean age of subjects in biological and mechanical valve groups were $41.47 \pm 3.02$ and $51.42 \pm 1.14$ years old respectively, while the mean age in the PTMC group was $45.12 \pm 11.91$ years old. There was a significant age difference between groups $(\mathrm{p}<0.001)$ indicating that the age in the mechanical valve group was significantly higher than biological $(\mathrm{p}=0.002)$ and PTMC $(\mathrm{p}=0.021)$ groups.

The median and IQR for follow up duration were 4.00 and 3.00 years respectively (ranging from 0 to 17 years). There was no significant difference in terms of follow up duration between intervention groups $(\mathrm{p}=0.229)$. The median and IQR for follow up intervals were 4.00 and 3.00 times respectively (ranging from 0.0 to 17.0 times). The characteristics of study subjects at follow up is presented in Table 2 and 3 . The history of PTMC was present in $18(13.3 \%)$ subjects among, whom $3(16.7 \%)$ were in biologic valve group, $13(72.2 \%)$ in mechanical valve group and $2(11.1 \%)$ in PTMC group. There was no significant difference between groups in terms of the frequency of secondary PTMC $(\mathrm{p}=0.368)$. Mean trans mitral gradient was significantly different between intervention groups $(\mathrm{p}<0.001)$ indicating a significant difference in $\mathrm{MG}$ between biological and mechanical group $(\mathrm{p}<0.001)$ and mechanical and PTMC groups ( $<<0.001)$ (Table 2). Readmission was recorded in $36(26.7 \%)$ of the subjects (Table $3)$. There was a significant difference in terms of mitral regurgitation severity $(\mathrm{p}<0.001)$, right ventricular size $(\mathrm{p}=0.014)$ and right ventricular function $(\mathrm{p}=0.02)$ between intervention groups (Table 3$)$. The NYHA class was significantly improved at follow up compared to baseline $(\mathrm{p}=0.039)$ (Figure 1) but there was no significant difference between intervention groups $(\mathrm{p}=0.505)$. 
Table 1. Baseline characteristics of study subjects

\begin{tabular}{|c|c|c|c|c|c|c|}
\hline \multicolumn{2}{|l|}{ Variable } & $\begin{array}{l}\text { Total } \\
\text { Frequency (\%) }\end{array}$ & $\begin{array}{l}\text { Biologic valve } \\
\text { Frequency (\%) }\end{array}$ & $\begin{array}{l}\text { Mechanical valve } \\
\text { Frequency (\%) }\end{array}$ & $\begin{array}{l}\text { PTMC } \\
\text { Frequency (\%) }\end{array}$ & $\mathrm{p}$ \\
\hline \multirow{2}{*}{ Gender } & Male & $29(21.5 \%)$ & $3(15.8 \%)$ & $20(24.1 \%)$ & $6(18.2 \%)$ & \multirow{2}{*}{0.633} \\
\hline & Female & $106(78.5 \%)$ & $16(84.2 \%)$ & $63(75.9 \%)$ & $27(81.8 \%)$ & \\
\hline \multicolumn{2}{|l|}{ Diabetes } & $17(12.6 \%)$ & $3(15.8 \%)$ & $11(13.3 \%)$ & $3(9.1 \%)$ & 0.749 \\
\hline \multicolumn{2}{|l|}{ Hypertension } & $21(15.6 \%)$ & $2(10.5 \%)$ & $14(16.9 \%)$ & $5(15.2 \%)$ & 0.787 \\
\hline \multicolumn{2}{|l|}{ Hyperlipidemia } & $20(14.8 \%)$ & $2(10.5 \%)$ & $15(18.1 \%)$ & $3(9.1 \%)$ & 0.400 \\
\hline \multicolumn{2}{|l|}{ Smoking } & $15(11.1 \%)$ & $0(0.0 \%)$ & $5(6.0 \%)$ & $10(30.0 \%)$ & $<0.001^{* *}$ \\
\hline \multicolumn{2}{|c|}{ Cerebrovascular accident } & $13(9.6 \%)$ & $4(21.1 \%)$ & $9(10.8 \%)$ & $0(0.0 \%)$ & $0.039^{*}$ \\
\hline \multicolumn{2}{|c|}{ Chronic kidney disease } & $0(0.0 \%)$ & $0(0.0 \%)$ & $0(0.0 \%)$ & $0(0.0 \%)$ & - \\
\hline \multicolumn{2}{|c|}{ Thyroid abnormality } & $6(4.4 \%)$ & $1(5.3 \%)$ & $5(6.0 \%)$ & $0(0.0 \%)$ & 0.358 \\
\hline \multicolumn{2}{|c|}{ Ischemic heart disease } & $8(5.9 \%)$ & $2(10.5 \%)$ & $6(20.7 \%)$ & $0(0.0 \%)$ & 0.074 \\
\hline \multirow{3}{*}{ Rhythm } & NSR & $81(60.0 \%)$ & $12(63.2 \%)$ & $43(51.8 \%)$ & $26(78.8 \%)$ & \multirow{4}{*}{$0.027 *$} \\
\hline & $\mathrm{AF}$ & $54(40.0 \%)$ & $7(36.8 \%)$ & $40(48.2 \%)$ & $7(21.2 \%)$ & \\
\hline & Paravalvular & $6(4.4 \%)$ & $1(5.3 \%)$ & $5(6.0 \%)$ & $0(0.0 \%)$ & \\
\hline \multirow{3}{*}{ MS severity } & Progressive & $10(7.4 \%)$ & $0(0.0 \%)$ & $0(0.0 \%)$ & $10(30.3 \%)$ & \\
\hline & Severe & $18913.3 \%)$ & $0(0.0 \%)$ & $0(0.0 \%)$ & $18(54.5 \%)$ & \multirow[t]{2}{*}{-} \\
\hline & Very severe & $5(3.7 \%)$ & $0(0.0 \%)$ & $0(0.0 \%)$ & $5(15.2 \%)$ & \\
\hline \multirow{8}{*}{$\begin{array}{l}\text { Type of } \\
\text { intervention }\end{array}$} & MVR & $51(37.8 \%)$ & - & - & - & \multirow{8}{*}{-} \\
\hline & PTMC & $33(24.4 \%)$ & - & - & - & \\
\hline & MVR TV repair & $17(12.6 \%)$ & - & - & - & \\
\hline & MVR AVR & $15(11.1 \%)$ & - & - & - & \\
\hline & MVR CABG & $6(4.4 \%)$ & - & - & - & \\
\hline & MVR TVR & $5(3.7 \%)$ & - & - & - & \\
\hline & $\begin{array}{l}\text { MVR AVR TV } \\
\text { repair }\end{array}$ & $5(3.7 \%)$ & - & - & - & \\
\hline & MVR AVR TVR & $3(2.2 \%)$ & - & - & - & \\
\hline \multirow{4}{*}{ NYHA } & Class I & $7(5.2 \%)$ & $3(15.8 \%)$ & $3(3.6 \%)$ & $1(3.0 \%)$ & \multirow{4}{*}{0.080} \\
\hline & Class II & $46(34.1 \%)$ & $6(31.6 \%)$ & $24(28.9 \%)$ & $16(48.5 \%)$ & \\
\hline & Class III & $42(31.1 \%)$ & $5(26.3 \%)$ & $26931.3 \%)$ & $11(33.3 \%)$ & \\
\hline & Class IV & $40(29.6 \%)$ & $5(26.3 \%)$ & $30(36.1 \%)$ & $5(15.2 \%)$ & \\
\hline
\end{tabular}

$\mathrm{NSR}=$ normal sinus rhythm, $\mathrm{AF}=$ atrial fibrillation, $\mathrm{MVR}=$ mitral valve replacement, $\mathrm{PTMC}=$ percutaneous transvenous mitral commissurotomy, $\mathrm{TV}=$ tricuspid valve, $\mathrm{AVR}=$ aortic valve replacement, $\mathrm{CABG}=$ coronary artery bypass graft, $\mathrm{TVR}=$ tricuspid valve replacement, $\mathrm{NYHA}=$ New York Heart Association classification

* Significant at $\alpha=0.05$

** Significant at $\alpha=0.01$

Table 2. Characteristics of study subjects at follow up

\begin{tabular}{|c|c|c|c|c|c|}
\hline Variable & $\begin{array}{l}\text { Total } \\
\text { Mean } \pm \text { SD }\end{array}$ & $\begin{array}{l}\text { Biological valve } \\
\text { Mean } \pm \text { SD }\end{array}$ & $\begin{array}{l}\text { Mechanical valve } \\
\text { Mean } \pm \text { SD }\end{array}$ & $\begin{array}{l}\mathrm{PTMC} \\
\text { Mean } \pm \mathrm{SD}\end{array}$ & $\mathrm{p}$ \\
\hline BMI $\left(\mathrm{kg} / \mathrm{m}^{2}\right)$ & $27.82 \pm 5.53$ & $26.16 \pm 3.14$ & $27.60 \pm 6.00$ & $29.35 \pm 5.09$ & 0.111 \\
\hline Visit intervals & $4.00(3.00)$ & $5.00(3.00)$ & $4.00(4.00)$ & $4.00(3.00)$ & 0.229 \\
\hline PAP (mmHg) & $34.21 \pm 8.60$ & $32.63 \pm 9.06$ & $35.49 \pm 9.11$ & $31.88 \pm 6.29$ & 0.085 \\
\hline $\mathrm{EF}(\%)$ & $54.51 \pm 7.36$ & $55.62 \pm 4.49$ & $54.29 \pm 7.91$ & $54.33 \pm 7.35$ & 0.719 \\
\hline MG & $4.81 \pm 1.65$ & $5.76 \pm 2.07^{\mathrm{a}}$ & $4.22 \pm 1.29^{\mathrm{ab}}$ & $5.73 \pm 1.55^{b}$ & $<0.001^{* *}$ \\
\hline TV annulus (??) & $3.19 \pm 0.45$ & $3.05 \pm 0.36$ & $3.21 \pm 0.50$ & $3.21 \pm 0.34$ & 0.355 \\
\hline
\end{tabular}

$\mathrm{BMI}=$ body mass index, $\mathrm{kg}=$ kilogram, $\mathrm{m}=$ meter, $\mathrm{PAP}=$ pulmonary artery pressure, $\mathrm{mm}=$ millimeter, $\mathrm{EF}=$ ejection fraction, $\mathrm{MG}=$ trans mitral gradient, $\mathrm{TV}=$ tricuspid valve, $\mathrm{PTMC}=$ percutaneous transvenous mitral commissurotomy

${ }^{\mathrm{a}} \mathrm{p}<0.001,{ }^{\mathrm{b}} \mathrm{p}<0.001$

* Significant at $\alpha=0.05$

** Significant at $\alpha=0.01$ 
Table 3. Characteristics of study subjects at follow up

\begin{tabular}{|c|c|c|c|c|c|c|}
\hline Variable & & $\begin{array}{l}\text { Total } \\
\text { Frequency (\%) }\end{array}$ & $\begin{array}{l}\text { Biological valve } \\
\text { Frequency (\%) }\end{array}$ & $\begin{array}{l}\text { Mechanical valve } \\
\text { Frequency (\%) }\end{array}$ & $\begin{array}{l}\text { PTMC } \\
\text { Frequency (\%) }\end{array}$ & $\mathrm{p}$ \\
\hline Readmission & & $36(26.7 \%)$ & $5(26.3 \%)$ & $24(28.9 \%)$ & $7(21.2 \%)$ & 0.698 \\
\hline \multirow{2}{*}{ Hemodynamic motion } & Normal & $96(07.0 \%)$ & $17(89.5 \%)$ & $79(98.8 \%)$ & $0(0.0 \%)$ & \multirow{2}{*}{0.093} \\
\hline & Abnormal & $3(3.0 \%)$ & $2(10.5 \%)$ & $1(1.3 \%)$ & $0(0.0 \%)$ & \\
\hline \multirow{4}{*}{ AS } & Normal & $117(86.7 \%)$ & $17(89.5 \%)$ & $70(84.3 \%)$ & $30(90.9 \%)$ & \multirow{5}{*}{0.844} \\
\hline & Mild & $1(0.7 \%)$ & $0(0.0 \%)$ & $1(1.2 \%)$ & $0(0.0 \%)$ & \\
\hline & Progressive & $13(9.6 \%)$ & $1(5.3 \%)$ & $9(10.8 \%)$ & $3(9.1 \%)$ & \\
\hline & Abnormal & $4(3.0 \%)$ & $1(5.3 \%)$ & $3(3.6 \%)$ & $0(0.0 \%)$ & \\
\hline \multirow{4}{*}{ AI } & Normal & $73(54.1 \%)$ & $8(42.1 \%)$ & $48(57.8 \%)$ & $17(51.5 \%)$ & \\
\hline & Mild & $41(30.4 \%)$ & $8(42.1 \%)$ & $23(27.7 \%)$ & $10(30.3 \%)$ & \multirow{5}{*}{0.209} \\
\hline & Moderate & $20(14.8 \%)$ & $2(10.5 \%)$ & $12(14.5 \%)$ & $6(18.2 \%)$ & \\
\hline & Transvalvular & $1(0.7 \%)$ & $1(5.3 \%)$ & $0(0.0 \%)$ & $0(0.0 \%)$ & \\
\hline \multirow{6}{*}{ Mitral regurgitation } & No & $101(74.8 \%)$ & $18(94.7 \%)$ & $78(94.0 \%)$ & $5(15.2 \%)$ & \\
\hline & Mild & $15(11.1 \%)$ & $0(0.0 \%)$ & $0(0.0 \%)$ & $15(45.5 \%)$ & \\
\hline & Moderate & $12(8.9 \%)$ & $0(0.0 \%)$ & $0(0.0 \%)$ & $12(36.4 \%)$ & \multirow[t]{4}{*}{$<0.001 * *$} \\
\hline & severe & $1(7.0 \%)$ & $0(0.0 \%)$ & $0(0.0 \%)$ & $1(3.0 \%)$ & \\
\hline & Paravalvular & $6(4.4 \%)$ & $1(5.3 \%)$ & $5(6.0 \%)$ & $0(0.0 \%)$ & \\
\hline & Progressive & $10(7.4 \%)$ & $0(0.0 \%)$ & $0(0.0 \%)$ & $10(30.3 \%)$ & \\
\hline \multirow[t]{2}{*}{ MS severity } & Severe & $18913.3 \%)$ & $0(0.0 \%)$ & $0(0.0 \%)$ & $18(54.5 \%)$ & \multirow[t]{2}{*}{-} \\
\hline & Very severe & $5(3.7 \%)$ & $0(0.0 \%)$ & $0(0.0 \%)$ & $5(15.2 \%)$ & \\
\hline \multicolumn{2}{|l|}{ Rheumatic TV involvement } & $38(28.1 \%)$ & $6(31.6 \%)$ & $28(33.7 \%)$ & $4(12.1 \%)$ & \multirow[t]{2}{*}{0.061} \\
\hline \multirow{4}{*}{$\mathrm{TR}$} & No & $11(8.1 \%)$ & $1(5.3 \%)$ & $7(8.4 \%)$ & $3(9.1 \%)$ & \\
\hline & Mild & $72(53.3 \%)$ & $13(68.4 \%)$ & $36(43.4 \%)$ & $23(69.7 \%)$ & \multirow{3}{*}{0.151} \\
\hline & Moderate & $32(23.7 \%)$ & $4(21.1 \%)$ & $22(26.5 \%)$ & $6(18.2 \%)$ & \\
\hline & Severe & $18(13.3 \%)$ & $1(5.3 \%)$ & $16(19.3 \%)$ & $1(3.0 \%)$ & \\
\hline \multirow{2}{*}{ Right ventricle size } & Normal & $104(77.0 \%)$ & $17(89.5 \%)$ & $57(68.7 \%)$ & $30(90.9 \%)$ & \multirow{2}{*}{$0.014^{*}$} \\
\hline & Abnormal & $31(23.0 \%)$ & $2(10.5 \%)$ & $26(31.3 \%)$ & $3(9.1 \%)$ & \\
\hline \multirow{2}{*}{ Right ventricular function } & Normal & $93(68.9 \%)$ & $17(89.5 \%)$ & $48(57.8 \%)$ & $28(84.8 \%)$ & \multirow[t]{4}{*}{$0.002 * *$} \\
\hline & Reduced & $42(31.1 \%)$ & $2(10.5 \%)$ & $35(42.2 \%)$ & $5(15.2 \%)$ & \\
\hline \multirow{6}{*}{ Symptoms } & None & $71(52.6 \%)$ & $10(52.6 \%)$ & $46(55.4 \%)$ & $15(45.5 \%)$ & \\
\hline & Dyspnea & $59(43.7 \%)$ & $7(36.8 \%)$ & $34(41.0 \%)$ & $18(54.5 \%)$ & \\
\hline & Edema & $2(1.5 \%)$ & $0(0.0 \%)$ & $2(2.4 \%)$ & $0(0.0 \%)$ & \multirow[t]{4}{*}{0.106} \\
\hline & Chest pain & $1(0.7 \%)$ & $1(5.3 \%)$ & $0(0.0 \%)$ & $0(0.0 \%)$ & \\
\hline & Fatigue & $1(0.7 \%)$ & $1(5.3 \%)$ & $0(0.0 \%)$ & $0(0.0 \%)$ & \\
\hline & Palpitation & $1(0.7 \%)$ & $0(0.0 \%)$ & $1(1.2 \%)$ & $0(0.0 \%)$ & \\
\hline
\end{tabular}

$\overline{\mathrm{AS}}=$ aortic stenosis, $\mathrm{AI}=$ aortic insufficiency, $\mathrm{MS}=$ mitral stenosis, $\mathrm{TR}=$ tricuspid regurgitation, $\mathrm{PTMC}=$ percutaneous transvenous mitral commissurotomy

* Significant at $\alpha=0.05$

** Significant at $\alpha=0.01$ 


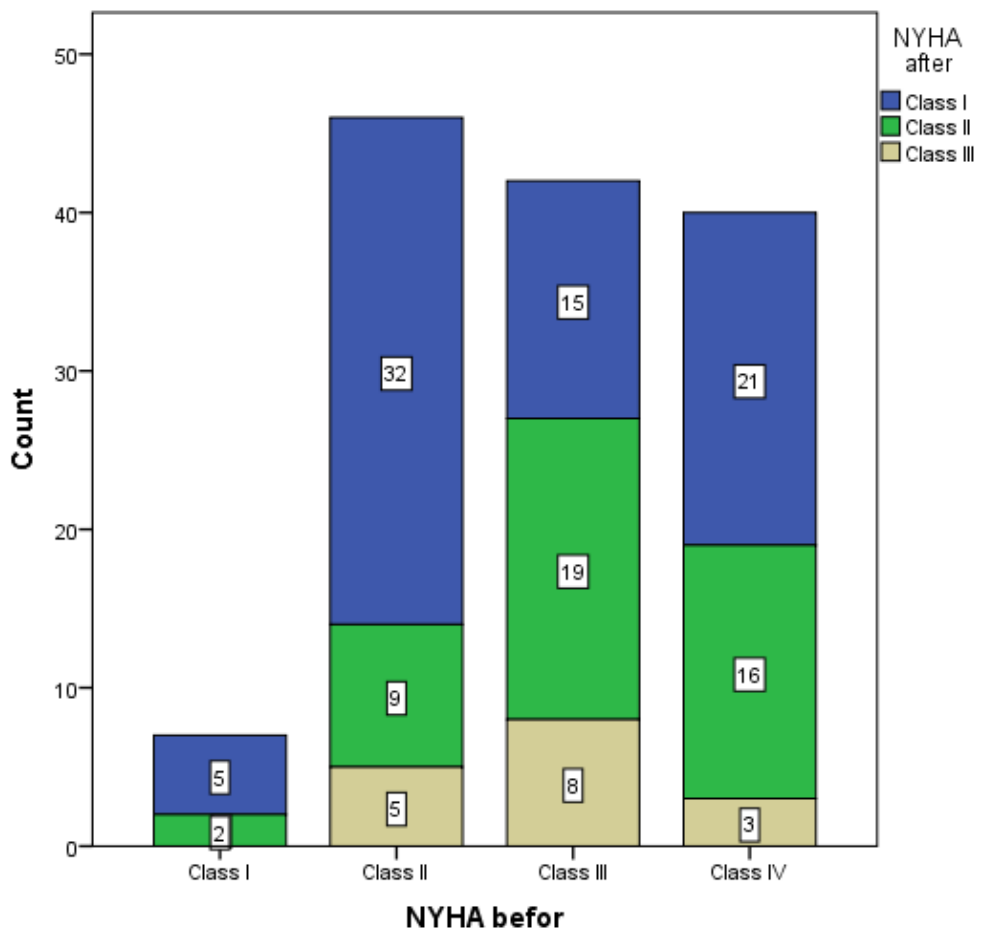

Figure 1. NYHA class distribution of subjects from baseline to the follow up

\section{Discussion}

The findings of this study revealed that majority of subjects underwent surgical valve replacement using mechanical valve (61.5\%) followed by PTMC (24.4\%). This finding was in contrast with the current trend in valvuloplasty, which indicates that PTMC is the first choice in developing countries (Kobayashi, 2019). As there was no significant difference in follow up duration between treatment interventions, the reason for the higher frequency of mechanical valve replacement might be due to the severity of MS and the existence of rheumatic involvement in other valves.

The findings of this study revealed that after a median of 4 years follow up $52.6 \%$ of the subjects were symptom free and the NYHA class was significantly improved in all treatment groups. This finding was in line with the findings of previous studies (Feldman et al., 2015; Bakir, Onan, Onan, Gul, \& Uslu, 2013). Readmission occurred in $26.7 \%$ of the subjects in this study. As this study included three types of treatment interventions, the findings of this study were not comparable with the findings of the previous studies that assessed only one treatment method. The rate of readmission has been previously reported to range between $25 \%$ to $78 \%$ (Franzone et al., 2017; Vassileva, Ghazanfari, Spertus, McNeely, Markwell, \& Hazelrigg, 2014).

This study also revealed that the prevalence of severe (7.0\%) and progressive (4.4\%) mitral regurgitation and severe tricuspid regurgitation (13.3\%) were low. This finding was also in line with the findings of previous studies (Feldman et al., 2015; Bakir, Onan, Onan, Gul, \& Uslu, 2013; Jackson et al., 2018).

Comparison of the outcomes between groups Echocardiographic findings of this study revealed that the size and function of the right ventricle were significantly higher in mechanical valve group at follow up compared to biologic valve and PTMC groups. Similar finding was observed in MS patients with comorbid and severe TR (Pubmeddev et al., 2019). Similarly, trans mitral gradient was significantly higher in biological valve and PTMC groups compared to mechanical valve group. This finding was in contrast with the finding of the study by Sharma et al. (2013), that reported no significant difference in trans mitral gradient between surgical valve replacement and PTMC in patients undergoing second time PTMC after prior valvuloplasty (Sharma et al., 2014). The reason for the difference in the findings of the studies might be due to the smaller sample size in the study by Sharma et al. (2013) and the inclusion of failed valvuloplasty cases. Furthermore, mitral regurgitation was significantly more prevalent in the PTMC group. This finding was in contrast with the findings of the study by Jackson et al. (2018) on 223 patients undergoing either PTMC or surgical repair and reported higher incidence of MR in the surgery 
group (Jackson et al., 2018). The reason for this controversy might be due to the larger sample size in the study by Jackson et al. (2018).

One of the limitations of this study was lack of information regarding the pre-existing valvular abnormalities and baseline echocardiographic assessment records. It is recommended for further researches to include patients with available echocardiographic assessments in order to be able to identify changes in these parameters. The strength of this study was the duration of follow up and the inclusion of the three main methods of MS treatment in the study. but there is a need for larger and multicenter studies to identify the general pattern of long-term outcomes among these three intervention types.

\section{Conclusion}

The findings of this study revealed that after the median of 4 years follow up, the functional class of MS patients decreased significantly in all groups but PTMC and biologic valves were prone to increased trans mitral gradient, while surgical valve replacement methods were prone to abnormal right ventricle size and decreased right ventricular function.

\section{Conflict of interests}

The authors declare that there is no conflict of interests regarding the publication of this paper.

\section{References}

Al Mosa, A. F., Omair, A., Arifi, A. A., \& Najm, H. K. (2016). Mitral valve replacement for mitral stenosis: A 15year single center experience. J Saudi Heart Assoc., 28(4), 232-238.

Bakir, I., Onan, B., Onan, I. S., Gul, M., \& Uslu, N. (2013). Is Rheumatic Mitral Valve Repair Still a Feasible Alternative? Tex Heart Inst J., 40(2), 163-9.

Fawzy et al. (2007). Seventeen years' clinical and echocardiographic follow up of mitral balloon valvuloplasty in 520 patients, and predictors of long-term outcome. J Heart Valve Dis., 16(5), 454-60.

Fawzy, M. E. (2009). Long-term results up to 19 years of mitral balloon valvuloplasty. Asian Cardiovasc Thorac Ann, 17(6), 627-33.

Feldman et al. (2015). Randomized comparison of percutaneous repair and surgery for mitral regurgitation: 5-year results of EVEREST II. J Am Coll Cardiol, 66(25), 2844-2854.

Franzone et al. (2017). Rates and predictors of hospital readmission after transcatheter aortic valve implantation. Eur Heart J., 38(28), 2211-7.

Jackson et al. (2018). Long-Term Outcomes Comparing Minimally Invasive Mitral Valve Repair versus Conventional Mitral Valve Surgery. World J Cardiovasc Surg., 8(8), 127-39.

Kobayashi, J. (2019). Opening of New Era for True Heart Valve Cure. J Transcatheter Valve Ther, 1(1), 1-2.

Palacios, I. F., Sanchez, P. L., Harrell, L. C., Weyman, A. E., \& Block, P. C. (2002). Which patients benefit from percutaneous mitral balloon valvuloplasty? Prevalvuloplasty and postvalvuloplasty variables that predict long-term outcome. Circulation, 105(12), 1465-71.

Marzangi A., Ahangarzadeh Rezaei, S., Ghareagaji Asl, R. (2018). Health Literacy and its Relation to Quality of Life in People with Heart Disease. International Journal of Pharmaceutical and Phytopharmacological Research (eIJPPR). 8(3): 25-32.

Pubmeddev et al. (2019). Percutaneous mitral valvuloplasty versus surgical treatment in mitral stenosis with severe tricuspid regurgitation. Retrieved from https://www.ncbi.nlm.nih.gov/pubmed/17846312

Saxena, A. (2018). Epidemiology and the natural history of mitral stenosis (pp. 11-20). In: Mitral Stenosis. CRC Press.

Selzer, A., \& Cohn, K. E. (1972). Natural history of mitral stenosis: A review. Circulation, 45(4), 878-890.

Sharma et al. (2014). Patient profile and results of percutaneous transvenous mitral commissurotomy in mitral restenosis following prior percutaneous transvenous mitral commissurotomy vs surgical commissurotomy. Indian Heart J., 66(2), 164-8.

Vassileva, C. M., Ghazanfari, N., Spertus, J., McNeely, C., Markwell, S., \& Hazelrigg, S. (2014). Heart failure readmission after mitral valve repair and replacement: Five-year follow-up in the Medicare population. Ann Thorac Surg., 98(5), 1544-50. 
Watanabe, N. (2016). Editorial: Percutaneous mitral valvotomy: Balloon made in Japan still dominates the world. J Cardiol Cases, 13(6), 169-70.

Wunderlich, N. C., Beigel, R., \& Siegel, R. J. (2013). Management of Mitral Stenosis Using 2D and 3D EchoDoppler Imaging. JACC Cardiovasc Imaging, 6(11), 1191-205.

\section{Copyrights}

Copyright for this article is retained by the author(s), with first publication rights granted to the journal.

This is an open-access article distributed under the terms and conditions of the Creative Commons Attribution license (http://creativecommons.org/licenses/by/4.0/). 